\title{
Severe barbiturate and paracetamol overdose: the simultaneous removal of both poisons by haemoperfusion
}

\author{
Michael Helliwell \\ M.B., M.R.C.P. \\ Poisons Unit, Guy's Hospital, London SE1 9RT
}

\begin{abstract}
Summary
Charcoal haemoperfusion was successful in the treatment of severe butobarbitone poisoning complicated by resistant hypotension. At the same time the rapid removal of paracetamol may have lessened the severity of the subsequent hepatic injury. The mechanism and management of shock associated with barbiturate poisoning, and the possible application of haemoperfusion in paracetamol poisoning are discussed.
\end{abstract}

\section{Introduction}

Charcoal haemoperfusion is an effective method of removing various poisons from the blood (Volans et al., 1977; Hampel and Widdop, 1978) and has advantages compared with haemodialysis (Vale et al.; 1975). Most experimental work and the subsequent clinical application of haemoperfusion relate to poisoning with one agent, usually a sedative or hypnotic drug (Widdop et al., 1975; Vale et al., 1975); as yet there have been no reports of the use of this technique in the treatment of mixed drug overdose. A case is now described in which haemoperfusion achieved the simultaneous removal of butobarbitone and paracetamol in a patient severely poisoned by both drugs.

\section{Case report}

A 69-year-old woman was admitted to hospital $12 \mathrm{hr}$ after taking an overdose of butobarbitone and paracetamol. Examination revealed her to be hypotensive (systolic blood pressure $60 \mathrm{mmHg}$ ) and unresponsive to painful stimuli. She was hypothermic with a rectal temperature of $32^{\circ} \mathrm{C}$ but respiration and initial blood gas determinations were satisfactory. Plasma concentrations of butobarbitone and paracetamol were $42 \mathrm{mg} / \mathrm{l}$ and $150 \mathrm{mg} / \mathrm{l}$ respectively, but as the overdose had occurred more than $10 \mathrm{hr}$ before her admission to hospital, specific antidotes to paracetamol were not given. During the next $9 \mathrm{hr}$ her condition deteriorated; she required mechanical ventilation and, despite an infusion of dopamine hydrochloride of $40 \mu \mathrm{g} / \mathrm{kg} / \mathrm{min}$, she remained markedly hypotensive. At this stage the plasma butobarbitone concentration had risen to $70 \mathrm{mg} / \mathrm{l}$ whilst the plasma paracetamol concentration remained exceedingly high at $127 \mathrm{mg} / \mathrm{l}$. The patient was therefore transferred to Guy's Hospital for haemoperfusion. On arrival she was breathing spontaneously but remained deeply unconscious (grade IV coma) and hypothermic (core temperature $31^{\circ} \mathrm{C}$ ). Her BP was unrecordable; further arterial blood gas determinations showed a marked metabolic acidosis with a $\mathrm{pH}$ of 7·12. Initial management consisted of elevating the central venous pressure to above $5 \mathrm{~cm} \mathrm{H}_{2} \mathrm{O}$ by the infusion of plasma. This was successful in raising the BP and enabled a reduction in the dopamine hydrochloride infusion (Fig. 1).

Haemoperfusion with a $2 \%$ acrylic hydrogelcoated charcoal column (Haemocol-100, Smith and Nephew Research Ltd, Harlow, Essex) was commenced and continued for $12 \mathrm{hr}$, during which time an infusion of colloids maintained the systolic BP above $80 \mathrm{mmHg}$ and allowed further reductions of the dopamine infusion. Heparin was given by infusion to achieve a plasma heparin concentration of $3 \mathrm{u} . / \mathrm{ml}$. There were no haemorrhagic complications and at the end of haemoperfusion heparinization was reversed by $100 \mathrm{mg}$ protamine. After $6 \mathrm{hr}$ of haemoperfusion the plasma paracetamol concentration had fallen to $40 \mathrm{mg} / \mathrm{l}$ (Fig. 2) and $6 \mathrm{hr}$ later the patient regained oculo-cephalic and oculo-vestibular reflexes. Two hours later she awoke from coma, by which time the plasma butobarbitone concentration had fallen to $38 \mathrm{mg} / \mathrm{l}$. The quantities of butobarbitone and paracetamol removed by haemoperfusion were $3.16 \mathrm{~g}$ and $4.75 \mathrm{~g}$ respectively. Over the next 7 days, biochemical tests of liver function revealed only moderate hepatic dysfunction with a maximum serum bilirubin and aspartate aminotransferase of $55 \mu \mathrm{mol} / 1$ and 393 i.u./l respectively and a prothrombin time of $40 \mathrm{sec}$ (control $12 \mathrm{sec}$ ). Apart from mild, transient jaundice there were no clinical stigmata of liver failure. However, 10 days 


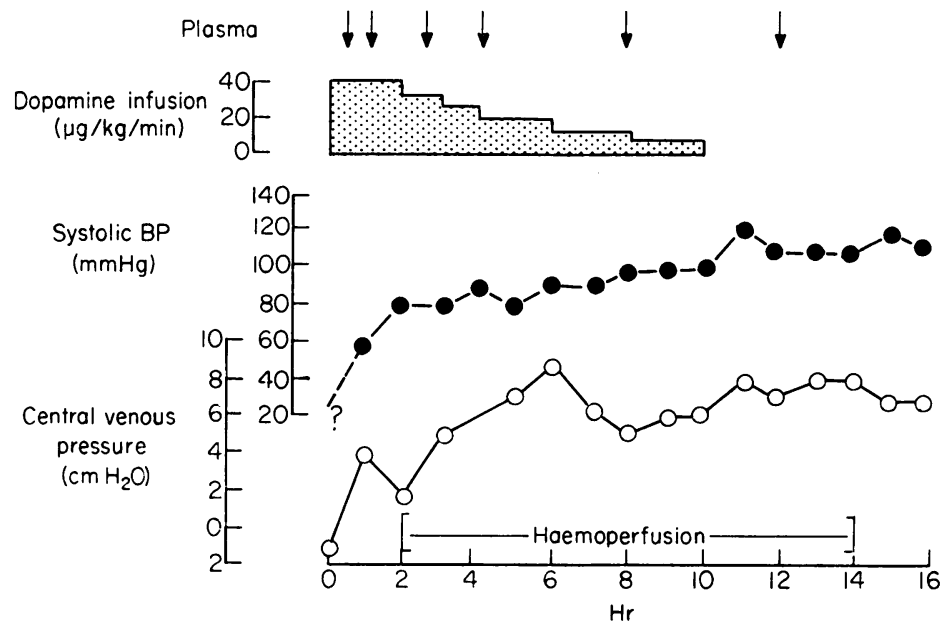

Fic. 1. Effect of volume repletion on systolic blood pressure.

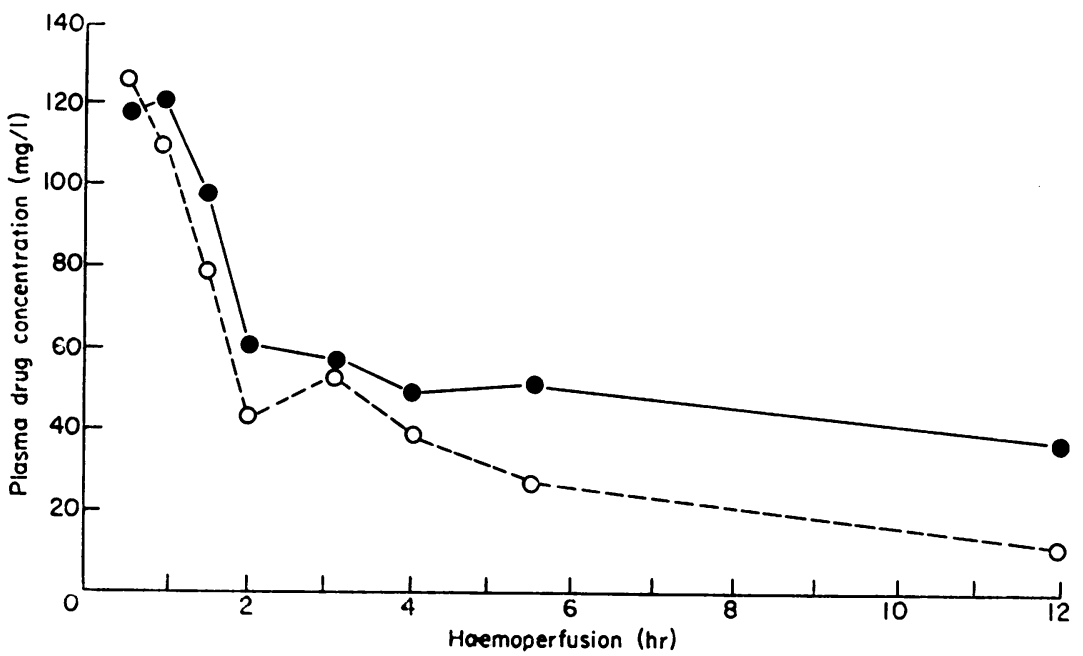

FIG. 2. Plasma levels of butobarbitone ( - - ) and paracetamol ( $\bigcirc--\bigcirc)$ during haemoperfusion.

following charcoal haemoperfusion, the patient suffered a large gastro-intestinal haemorrhage from a bleeding duodenal ulcer and required emergency surgery. Her postoperative recovery was uneventful and by the time of discharge from hospital her liver function tests had returned to normal apart from a slight elevation of the serum alkaline phosphatase of 142 i.u./l.

\section{Discussion}

In terms of management, the case described presented dual problems, namely the complications of severe barbiturate poisoning (of which hypotension was the chief concern) and the likelihood of the patient sustaining severe, if not fatal, paracetamo on induced liver damage judging from the initia $\overline{\hat{h}}$ plasma paracetamol level.

Shock associated with severe barbiturate intoxicaN tion is due mainly to an expansion of the capacity of the vascular bed thereby causing a relative hypoe volaemic state (Shubin and Weil, 1965) and it is this disparity between vascular capacity and volume that accounts for the reduction in cardiac output and? subsequent hypotension. Treatment should therefore be directed towards restoring an effective plasma volume by the infusion of colloids (Shubin and Weil 
1971). It is probable that the large doses of dopamine initially given may have contributed significantly to the patient's metabolic acidosis since infusion rates of greater than $10 \mu \mathrm{g} / \mathrm{kg} / \mathrm{min}$ stimulate $\alpha$-adrenergic receptors and cause vasoconstriction (Goldberg, 1977) but with the central venous pressure maintained at between $5-10 \mathrm{~cm} \mathrm{H}_{2} \mathrm{O}$ by the infusion of plasma, inotropic support could be gradually withdrawn without any resultant fall in BP.

The other concern was the probability of the patient developing severe hepatic damage as a consequence of the paracetamol overdose. Not only were the plasma paracetamol concentrations exceedingly high in relation to the time after ingestion (Gazzard et al., 1977) but the pre-perfusion plasma paracetamol half-life of $32 \mathrm{hr}$ indicated a poor prognosis (Prescott et al., 1971). Furthermore, the patient had been taking butobarbitone as a hypnotic for many years, thereby making herself particularly vulnerable to the hepatotoxic effect of paracetamol (Wright and Prescott, 1973). Fortunately she emerged with only moderate hepatic damage, as assessed biochemically (Gazzard et al., 1977).

Gazzard et al. (1974) found haemoperfusion to be of little value in the early treatment of paracetamol poisoning, although in this study the use of $10 \%$ coated charcoal probably accounted for the small quantities of paracetamol extracted. Specific antidotes however are effective in limiting the degree of hepatic damage (Crome et al., 1976a; Douglas, Hamlyn and James, 1976; Prescott et al., 1977) but are generally accepted as being contra-indicated more than $10 \mathrm{hr}$ following the ingestion of paracetamol (Editorial, 1975; Crome et al., 1976b). Reduction in hepatic perfusion during the stage of hypotension and competition by butobarbitone for microsomal enzymes may have diminished the metabolism of paracetamol to the toxic metabolite; even so this case suggests that haemoperfusion at a late stage may afford some protection to the liver in patients severely poisoned with paracetamol.

\section{Acknowledgment}

I wish to thank Dr Roy Goulding and Dr Brian Widdop for their helpful advice and Mr E. Essex who performed the plasma drug analyses.
References

Crome, P., Vale, J.A., Volans, G.N., Widdop, B. \& GouldiNG, R. (1976a) Oral methionine in the treatment of severe paracetamol (acetaminophen) overdose. Lancet, ii, 829.

Crome, P., Volans, G.N., Vale, J.A., Widdop, B., GouldING, R. \& Williams, R. (1976b) The use of methionine for acute paracetamol poisoning. Journal of International Medical Research, 4 (suppl. 4), 105.

Douglas, A.P., Hamlyn, A.N. \& James, O. (1976) Controlled trial of cysteamine in treatment of acute paracetamol (acetaminophen) poisoning. Lancet, i, 111.

EDITORIAL (1975) Paracetamol hepatotoxicity. Lancet, ii, 1189.

Gazzard, B.G., Willson, R.A., Weston, M.J., Thompson, R.P.H. \& Williams, R. (1974) Charcoal haemoperfusion for paracetamol overdose. British Journal of Clinical Pharmacology, 1, 271.

Gazzard, B.G., Hughes, R.D., Widdop, B., Goulding, R. Davis, M. \& Williams, R. (1977) Early prediction of the outcome of a paracetamol overdose based on an analysis of 163 patients. Postgraduate Medical Journal, 53, 243.

GolDBERG, L.I. (1977) Recent advances in the pharmacology of catecholamines. Intensive Care Medicine, 3, 233.

HAMPEL, G. \& Widdop, B. (1978) Experience with haemoperfusion in the treatment of acute drug intoxication. Proceedings of the European Society for Artificial Organs, 5, 202.

Prescott, L.F., Wright, N., Roscoe, P. \& Brown, S.S. (1971) Plasma paracetamol half-life and hepatic necrosis in patients with paracetamol overdosage. Lancet, i, 519.

Prescott, L.F., Park, J., Ballantyne, A., Adriaessens, P. \& Proudfoot, A.T. (1977) Treatment of paracetamol (acetaminophen) poisoning with $\mathrm{N}$-acetylcysteine. Lancet, ii, 432.

Shubin, H. \& WeIL, M.H. (1965) The mechanism of shock following suicidal doses of barbiturates, narcotics and tranquilizer drugs, with observations on the effects of treatment. American Journal of Medicine, 38, 853.

Shubin, H. \& WeIL, M.H. (1971) Shock associated with barbiturate intoxication. Journal of the American Medical Association, 215, 263.

Vale, J.A., Rees, A.J., Widdop, B. \& Goulding, R. (1975) Use of charcoal haemoperfusion in the management of severely poisoned patients. British Medical Journal, 1, 5.

Volans, G.N., Vale, J.A., Crome, P., WiddoP, B. \& GouldING, R. (1977) The role of charcoal haemoperfusion in the management of acute poisoning by drugs. In: Strathclyde Bioengineering Seminars-Artificial Organs (Ed. by Kenedi, R.M., Courtney, J.M., Gaylor, J.D.S. \& Gilchrist, T.), p. 179. MacMillan, London.

Widdop, B., MrdD, R.K., Braithwaite, R.A., Rees, A.J. \& GouldING, R. (1975) Experimental drug intoxication: treatment with charcoal haemoperfusion. Archives of Toxicology, 34, 27.

Wright, N. \& Prescott, L.P. (1973) Potentiation by previous drug therapy of hepatotoxicity following paracetamo! overdose. Scottish Medical Juurnal, 18, 56. 